\title{
Drug shortage registry under discussion
}

$\mathrm{T}$

he Canadian Pharmacists Association is negotiating with drug manufacturers, hospital pharmacists and the Canadian Medical Association to create a national reporting system that would track drug shortages.

"We still have a long way to go, but the discussions have started," says Jeff Morrison, director of government relations and public affairs for the Canadian Pharmacists Association.

Recent shortages of cancer drugs such as carboplatin, cytarabine, dacarbazine and vinorelbine, as well as periodic shortages of drugs ranging from some common antibiotics to anesthetics and antinausea medications have prompted physicians, pharmacists and other health care professionals to call for a national registry or portal modelled on one hosted by the American Society of Health System Pharmacists.

In the United States, a physician or pharmacist encountering a drug shortage can inform the American Society of Health System Pharmacists, which then contacts manufacturers to confirm the shortage and obtain an estimated date when the drug might be available again.

"It works great - it's highly valued by both doctors and pharmacists in the States, and we have nothing like it in Canada," says Morrison. "That's what we're trying to create."

A central registry that lists available alternatives to drugs in short supply would also save pharmacists and health care professionals time, says Myrella Roy, executive director of the Canadian Society of Hospital Pharmacists.

The pharmacists and interested stakeholders, who will meet again in June, have spoken to Health Minister Leona Aglukkaq and secured her support, he says. But they have not yet determined a funding source for the registry.

"Minister Aglukkaq recently tasked Health Canada with exploring options for improved management of drug shortages, and has written to industry to ensure a collaborative approach on this

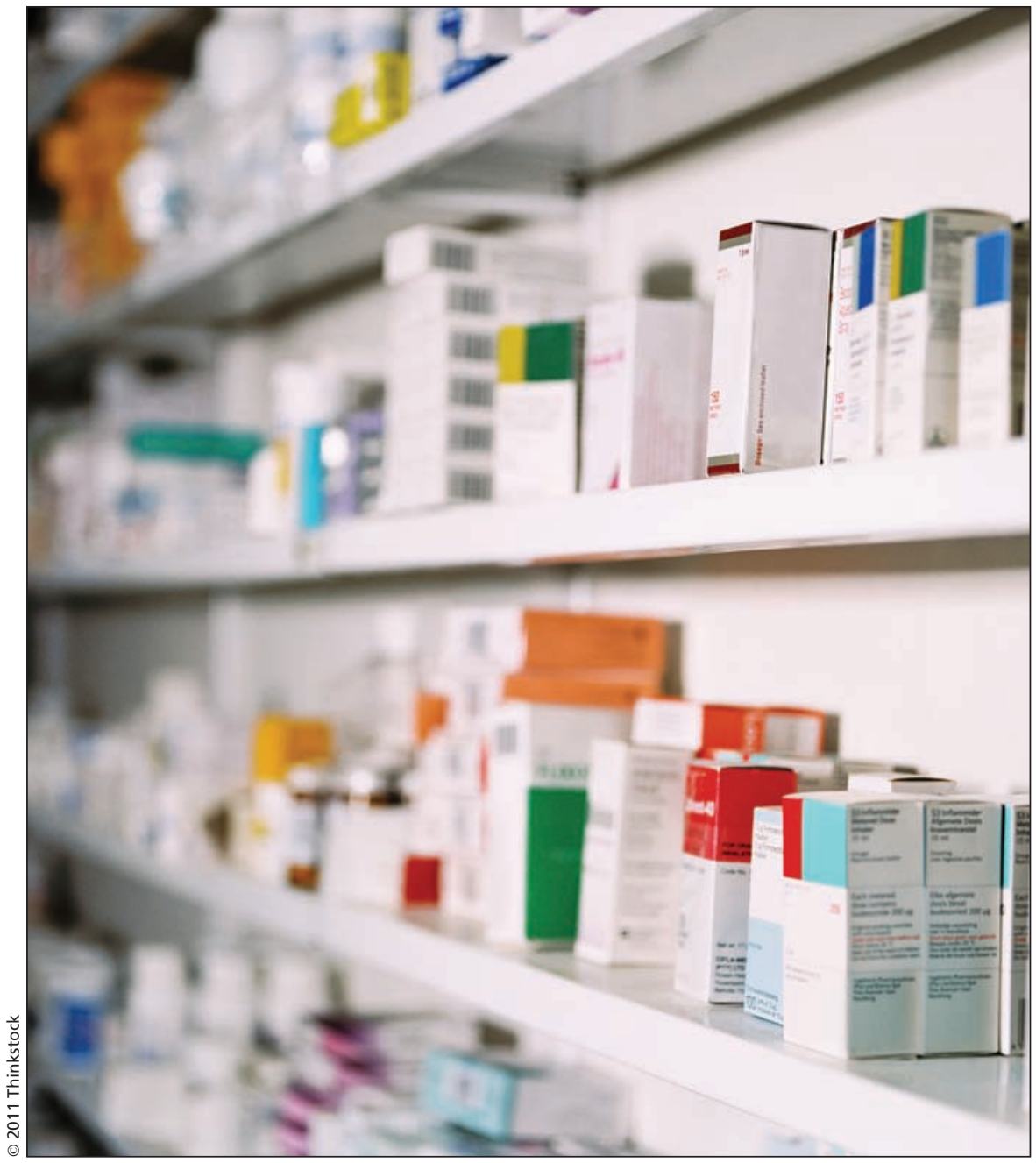

Pharmacists believe a central registry or website could help them keep their shelves stocked and better plan for, and cope with, drug shortages such as those now being seen for cancer drugs such as carboplatin, cytarabine, dacarbazine and vinorelbine.

important issue," Health Canada writes in an email.

Currently, although manufacturers may contact Health Canada about shortages, they are not required to do so something some physicians feel needs to change.

Advance warning of pending shortages of carboplatin would have helped the Juravinski Cancer Centre in Hamilton, Ontario, which in May found itself without any carboplatin to treat patients with breast and lung cancer, says Dr. Peter Ellis, an oncologist at the centre.
"We got three days' notice that there was no drug supply," Ellis says. "We were told there was a manufacturing issue and there wasn't any additional information forthcoming. There are varying potential explanations for that, but one would have to assume the manufacturer had more warning of this than we did."

Although Ellis' patients had their treatments delayed or modified for only about a week, he is worried that if these shortages persist they could affect the quality of patient care.

Some form of federal government 
intervention may be required in order to achieve more transparency about drug availability, Ellis says.

Dr. Katia Tonkin, an oncologist at Edmonton's Cross Cancer Institute in Alberta, goes even further, calling for mandatory reporting of pending shortages and a central agency to monitor supply.

Such an agency could seek out other sources for crucial drugs, Tonkin says. "The company would have to be told, 'If you can't meet your commitment six months ahead, we need to know'."
Alberta oncologists have rationed carboplatin to what are deemed "curable" patients, in order to conserve the province's supply of the drug. Patients with more advanced cancers receive cisplatin, (which can be more damaging to the kidneys and causes more vomiting) in their chemotherapy cocktails, Tonkin says.

Alberta Health Services decided to ration carboplatin because of forecasts that it would otherwise run out of the drug, says Dr. Paul Grundy, the province's senior medical director for cancer care. "By doing that we believe we are going to make it through the shortage without running out or compromising people's care."

Grundy also believes that a central registry or website could help in planning for and coping with shortages. As importantly, a national and even bilateral dialogue with stakeholders in Canada and the United States is needed to examine the causes of the shortages, he says. "People need to get their heads together." - Laura Eggertson, Ottawa, Ont.

CMAJ 2011. DOI:10.1503/cmaj.109-3904 